\title{
Sosyal Medya Bozukluğu: Üniversite Öğrencileri Üzerine Bir Araştırma
}

\author{
DOI: 10.26466/opus.521522 \\ * \\ Cağdas Caz ${ }^{*}$ - Sait Bardakç1 ${ }^{* *}$
}

* Araş.Gör. Dr, Yozgat Bozok Üniversitesi, Beden Eğitimi ve Spor Yüksekokulu/ Yozgat / Türkiye E-Posta: cazcagdas@gmail.com

ORCID: 0000-0003-0262-6114

** Dr. Öğretim Üyesi., Sivas Cumhuriyet Üniversitesi, İ̈BF/İşletme Bölümü/ Sivas/ Türkiye

E-Posta: sait bardakci@hotmail.com

ORCID: $\underline{0000-0003-3720-5029}$

\section{Öz}

Gelişen teknolojiye bağlı olarak araç/gereçlerin artması ile birlikte internet kullanımı hayatımızın ayrılmaz bir parçası olmuştur. İnternet kullanımında meydana gelen gelişmelere bağhl olarak sosyal medya sayısında artış gözlenmiştir. Kimi birey sosyal medyayı faydalı bir şekilde kullanırken, kimi birey ise farklı amaçlar için kullanmaktadır. Bu düşünceye istinaden çalışmanın amacı, üniversite öğrencilerinin sosyal medya kullanım bozukluğunu incelemektir. Bu amaç doğrultusunda çalışmaya, 704 üniversite öğrencisi (188 erkek, 516 kadın) katılım göstermiştir. Çalışmada veri toplama aracı olarak; Savcl, Ercengiz ve Aysan (2018) tarafindan geliştirilen "Sosyal Medya Bozukluğu Ölçeği" ile araştırmacıla tarafindan oluşturulan "Kişisel Bilgi Formu" kullanılmıştır. Veriler; betimsel istatistikî yöntemler, bağımsız gruplar için $t$ testi, üç veya daha fazla kategoriden oluşan değişkenler için ise tek yönlü varyans (ANOVA) ile analiz edilmiştir. Araştırma sonucunda; öğrencilerin sosyal medya bozukluk düzeyi cinsiyetlerine göre anlaml farklilı göstermemektedir. Ancak, sosyal medyanın bozukluğunun farklı bölümlerde öğrenim gören öğrenciler arasında, en sık kullanılan sosyal medyada, sosyal medyanın kullanım amacında farklılık yarattı̆̆ı tespit edilmiştir.

Anahtar Kelimeler: Sosyal medya bozukluğu,Üniversite öğrencisi, Sosyal ă̆ 


\title{
Social Media Disorder: A Research on University Students
}

\begin{abstract}
The use of the Internet with the increase of tools depending on the developing technology has become an integral part of our lives. There has been an increase in the number of social media due to the developments in internet usage. Some individuals use social media in a beneficial way, while others use it for different purposes. Based on this idea, the aim of this study is to examine social media usage disorder of university students. For this purpose, 704 univetsity students (188 male, 516 female) participated in the study. As a data collection tool; Social Media Disorder Scale "developed by the Prosecutor, Ercengiz and Aysan (2018) and "Personal Information Form" was used by the researchers. Data; Descriptive statistical methods were analyzed with $t$-test for independent groups and one-way variance (ANOVA) for three or more categories. As a result of the research; social media disorder did not make any difference between male and female students. However, it has been determined that the social media has a difference in the use of social media in the most frequently used social media among the students studying in different departments.
\end{abstract}

Keywords: Social media disorder, University Students, Social network 


\section{Giriş}

Günümüzde internet, sosyal medya ve mobil teknolojiler artık günlük yaşantımızın vazgeçilmez bir parçasıdır. Sosyal medya, kendine yetecek kadar bilgisayar, tablet ve akıllı telefon kullanabilen herkesin ilgi odağ1 haline gelmiştir (Hazar, 2011). Özellikle gençler ve üniversite öğrencileri, kolay ve hızlı erişebilme özelliğine sahip bir kitle iletişim aracı olan internet ve sosyal medyayı gün geçtikçe akademik veya diğer amaçları için sıklıkla kullanmaktadırlar. Bu araçlar sadece iyi bir bilgi kaynağı olmakla kalmamakta, aynı zamanda sosyal etkileşimler, oyun, eğlence gibi diğer amaçlar için de iyi bir başvuru kaynağı haline gelmişlerdir (Singh ve Barmola, 2015).

Sosyal medya ağları ya da siteleri internet teknolojisinin günlük yaşamımıza kattığı ve her geçen gün kullanıcı sayısının arttığ1 popüler kültürün öğelerinden biridir. Gittikçe kullanımı artan sosyal medya, karşılıklı konuşmaları geliştirerek insanların iletişim biçimini değiştiren web tabanlı bir teknolojidir ve temelde kişinin şahsi kullanımlarını, performansını ve üretkenliğini kişiselleştirebilecekleri bir alandır (Cabral, 2011). Teknolojide gelinen noktaya istinaden sosyal paylaşım ağları toplum bireylerinin ilgi odağı olmakta, sanal dünya gerçek hayatın önüne geçmektedir (Kırık, Arslan, Çetinkaya, ve Gül 2015).

Kişiler özellikle gençler internet teknolojisini sosyal medyaya girmek için kullanmaktadır. Sosyal medya kullanımlarında ebeveyn, öğretmen denetimi olmadığı durumlarda ergenlerin olumsuz içeriklerle karşılaşması ve bu içeriklerden etkilenme olasılığı yüksektir. Gündelik haytta sıklıkla kullanılan sosyal medya uygulamaları milyonlarca insan tarafından kullanılmaktadır (Ergenç, 2011; Hazar, 2011). Bu yaygın kullanıma rağmen net bir tanımlamaya sahip olmayan sosyal medya kavramı, bazı çalışmalarda Web 2.0 ile eşdeğer görülmektedir (Dikme, 2013). Bazı çalışmalarda (İşlek, 2012; Yayla, 2010) ise bu iki kavramın farklılığına vurgu yapılmıştır.

Teknolojide yaşanan gelişmeler, fırsatlar sunmanın yanı sıra bazı riskleri de beraberinde getirmiştir. Bu risklerin başında, geleneksel akran zorbalığının okul ortamından siber uzama taşınmasıyla ortaya çıkan siber zorbalık olgusu gelmektedir (Patchin ve Hinduja, 2006). Bu risklerden biri de sosyal medya bozukluğudur (Savc1, Ercengiz ve Aysan, 2018). Sosyal 
medya bozukluğu/bağımlılığı DSM-V'te bir bozukluk olarak tanımlanmamaktadır. Ancak, literaturde sosyal medya bağımlılı̆̆ı bir davranışsal bağımlılık olarak değerlendirilmektedir (Griffiths ve Szabo, 2014; Kuss ve Griffiths, 2011). İlgili literatür incelendiğinde farklı alanlarda farklı çalışmaların, Savcı ve ark., (2018); Akkaya ve Zerenler (2017); Sarıçam ve Adam-Karduz (2018); Ünlü (2018); Çiftçi (2018); Lim ve An (2018); Mitchell, Santarossa ve Woodruff, (2018); Göksel ve Serarslan (2015), yapıldığı görülmektedir.

Sosyal medya ağları, günümüz dünyasında hem iletişim kurma hem de günceli takip etme açısından önemlidir. Bu ağlar, öğrencilerin birbirleri ile haberleşme, ders notlarını ve ders slaytlarını iletme açısından önem taşımaktadır. Ancak, sosyal medya ağları faydalı olduğu kadar, bireylerin zamanlarını fazlasıyla alması ve işlevi dışında kullanılması gibi olumsuz sonuçlara da sebep olmaktadır. Mevcut çalışma, üniversite öğrencilerinin sosyal medya bozukluk düzeylerinin belirlenmesi açısından önem taşımaktadır. Ayrıca, yapılacak çalışmalara kaynak oluşturması bakımından da literatüre katkı sağlayacağı düşünülmektedir. Bu düşüncelerden hareketle çalışmanın amacl; üniversite öğrencilerinin sosyal medya bozukluk düzeylerinin belirlenmesidir. Bu amaç doğrultusunda bazı sorulara yanıt aranmıştır: (1) Öğrencilerin sosyal medya bozukluğu ne düzeydedir? (2) Sosyal medya bozukluğu, cinsiyet'e göre anlamlı bir şekilde farklılaşmakta mıdır? (3) Sosyal medya bozukluğu, öğrenim görülen bölüm/fakülteye göre farklılaşmakta mıdır? (4) Sosyal medya kullanım süresi, sosyal medya bozukluğu üzerinde manidar farklılık yaratmakta mıdır? (5) En sık kullanılan sosyal medyanın sosyal medya bozukluğu üzerinde anlamlı etkisi var mıdır? (6) Öğrencinin sosyal bir yapıya sahip olması, sosyal medya bozukluğunda farklılık yaratmakta mıdır? (7) Öğrencilerin sosyal medya kullanım amaçları, sosyal medya bozukluğunda manidar farklılık yaratmakta mıdır? 


\section{Yöntem}

\section{Araştırmanın Modeli}

Araştırma kapsamında kullanılan betimsel tarama modeli, iki ya da daha fazla değişkenin değişim varlığını veya derecesini belirlemeyi amaçlamaktadir (Karasar, 1991).

\section{Evren ve Örneklem}

Araştırmanın evrenini; Yozgat Bozok Üniversitesi öğrencileri oluşturmaktadır. Araştırmanın örneklemi ise Sağlık Hizmetleri Meslek Yüksekokulu, Beden Eğitimi ve Spor Yüksekokulu ve Eğitim fakültesinde öğrenim gören toplam 704 öğrenciden oluşmaktadır. Araştırmanın çalışma grubunun belirlenmesinde kolayda örnekleme yöntemi kullanılmıştır. Kolayda örnekleme yöntemi hızlı, ucuz ve kolay yoldan veri toplamaya imkân tanıyan bir örnekleme tekniğidir (Gürbüz ve Şahin, 2014).

\section{Veri Toplama Araçları}

Araştırmada; Savcı, Ercengiz ve Aysan (2018) tarafından geliştirilen "Sosyal Medya Bozukluğu Ölçeği" ile araştırmacılar tarafından oluşturulan "Kişisel Bilgi Formu" kullanılmıştır. Ölçek, toplam 9 maddeden oluşan ve 5'li Likert tipinde bir ölçektir (Her Zaman:5, Sıklıkla:4, Bazen:3, Nadiren:2 ve Hiçbir Zaman:1). Ölçekten alınabilecek en yüksek puan 45, en düşük puan ise 9'dur. Mevcut ölçeğin yapı geçerliği Açımlayıcı Faktör Analizi (AFA) ve Doğrulayıcı Faktör Analizi (DFA) ile incelenmiştir. AFA sonucunda elde edilen tek faktörlü yapı iki ayrı örneklemde Doğrulayıcı Faktör Analizi (DFA) ile test edilmiştir. DFA sonucunda tek faktörlü ölçeğin modelinin her iki örneklemde de iyi uyum değerlerine sahip olduğu görülmüştür. Ölçeğin ölçüt bağlantılı geçerliği sosyal medya kullanım süresi, sosyal medya hesap sayısı, öz-disiplin, dürtüsellik, pozitif duygulanım, negatif duygulanım ve sosyal bağlılık ile incelenmiştir. Ölçeğin güvenirliği test- tekrar test yöntemi ve üç farklı örneklemde Cronbach's $\alpha$ iç tutarlık güvenirlik katsayısı ile incelenmiştir. Analiz sonucunda Cronbach's $\alpha$ iç tutarlık güvenirlik katsayıları ve t- 
tekrar test güvenirlik katsayısının yeterli düzeyde olduğu görülmüştür (Savcl, Ercengiz ve Aysan, 2018).

\section{Verilerin Toplanması}

Verilerin toplanması, üniversite öğrencilerinden ders dönemi içerisinde gerçekleşmiştir. Önecelikle veri toplama aracı hakkında bilgilendirme yapılmış sonrasında ise çalışmaya katılmak isteyen öğrencilerden veriler toplanmıştır.

\section{Verilerin Analizi}

Elde edilen verilerin normallik varsayımının sınanması için KolmogorovSmirnov testi kullanılmıştır. Bununla birlikte verilerin normallik göstergesi olarak çarpıklık ve basıklık katsayıları da dikkate alınmıştır. Üniversite öğrencilerinin sosyal medya bozukluğu puanlarının demografik özelliklerinin farklı kategorilerine göre karşılaştırılmasında kategori sayısı dikkate alınmıştır. Buna göre sosyal medya bozukluğu puanlarının karşılaştırılmasında iki kategoriden oluşan değişkenler için bağımsız gruplar için $t$ testi, üç veya daha fazla kategoriden oluşan değişkenler için ise tek yönlü varyans analizi (Oneway Analysis of Variance-ANOVA) kullanılmıştır. İkiden fazla parametrik ana kütle ortalamasının birbirine eşit olup olmadığını test etmek için ANOVA testi kullanılmaktadır (Karagöz, 2016). ANOVA sonucunda oluşan farklılığın hangi gruplar arasında kaynaklandığını saptamak amacıyla çoklu karşılaştırma (Post Hoc.) testleri kullanılmıştır. Kullanılacak çoklu karşılaştırma testinin belirlenmesinde Levene varyansların homojenliği testi dikkate alınmıştır. Bu test sonucunda eğer grup varyansları homojen ise Tukey, grup varyansları homojen değilse Tamhane T2 çoklu karşılaştırma testi kullanılmıştır.

\section{Bulgular}

Araştırmada üniversite öğrencilerinin sosyal medya kullanım bozukluğuna ilişkin demografik özelliklerinin betimlendiği değerler tabloda yer almaktadır. 
Tablo 1. Demografik Değişkenlere İlişkin Frekans Tablosu

\begin{tabular}{|c|c|c|}
\hline Cinsiyet & Frekans & Yüzde (\%) \\
\hline Erkek & 188 & 26,7 \\
\hline Kadın & 516 & 73,3 \\
\hline Toplam & 704 & 100,0 \\
\hline Akademik Birim & Frekans & Yüzde (\%) \\
\hline Sağlık Hizmetleri MYO & 484 & 68,8 \\
\hline BESYO & 96 & 13,6 \\
\hline Eğitim Fakültesi & 124 & 17,6 \\
\hline Toplam & 704 & 100,0 \\
\hline Sinıf & Frekans & Yüzde (\%) \\
\hline 1. Sinif & 503 & 71,4 \\
\hline 2. Sinif & 142 & 20,2 \\
\hline 3. Sinif & 43 & 6,1 \\
\hline 4. Sinif & 10 & 1,4 \\
\hline Uzatmalı & 6 & 9 \\
\hline Toplam & 704 & 100,0 \\
\hline Sosyal Medya Günlük Kullanım Süresi & Frekans & Yüzde (\%) \\
\hline 0-1 Saat & 57 & 8,1 \\
\hline 2-3 Saat & 263 & 37,4 \\
\hline 4-6 Saat & 271 & 38,5 \\
\hline 7 Saat ve Üzeri & 113 & 16,1 \\
\hline Toplam & 704 & 100,0 \\
\hline \multicolumn{3}{|l|}{ Sahip Olunan Sosyal Medya Hesapları } \\
\hline Facebook & Frekans & Yüzde (\%) \\
\hline Kullanmiyorum & 609 & 86,5 \\
\hline Kullaniyorum & 95 & 13,5 \\
\hline Toplam & 704 & 100,0 \\
\hline Instagram & Frekans & Yüzde (\%) \\
\hline Kullanmiyorum & 146 & 20,7 \\
\hline Kullaniyorum & 558 & 79,3 \\
\hline Toplam & 704 & 100,0 \\
\hline Twitter & Frekans & Yüzde (\%) \\
\hline Kullanmiyorum & 604 & 85,8 \\
\hline Kullaniyorum & 100 & 14,2 \\
\hline Toplam & 704 & 100,0 \\
\hline Whatsapp & Frekans & Yüzde (\%) \\
\hline Kullanmiyorum & 90 & 12,8 \\
\hline Kullaniyorum & 614 & 87,2 \\
\hline Toplam & 704 & 100,0 \\
\hline Hepsi & Frekans & Yüzde (\%) \\
\hline Kullanmiyorum & 636 & 90,3 \\
\hline Kullaniyorum & 68 & 9,7 \\
\hline Toplam & 704 & 100,0 \\
\hline En Sik Kullanılan Sosyal Medya & Frekans & Yüzde (\%) \\
\hline
\end{tabular}




\begin{tabular}{|c|c|c|}
\hline Facebook & 6 & 9 \\
\hline Instagram & 354 & 50,3 \\
\hline Twitter & 15 & 2,1 \\
\hline Whatsapp & 320 & 45,5 \\
\hline Diğer & 9 & 1,3 \\
\hline Toplam & 704 & 100,0 \\
\hline Sosyallik & Frekans & Yüzde (\%) \\
\hline Evet & 456 & 64,8 \\
\hline Hayır & 248 & 35,2 \\
\hline Toplam & 704 & 100,0 \\
\hline Sosyal Medya Kullanım Amacı & Frekans & Yüzde (\%) \\
\hline Düşünce ve Bilgi Paylaşmak & 28 & 4,0 \\
\hline Zaman Geçirmek & 335 & 47,6 \\
\hline Kişileri Takip Etmek & 21 & 3,0 \\
\hline Güncel Haber ve Bilgileri Takip Etmek & 164 & 23,3 \\
\hline İletişim Kurmak & 156 & 22,2 \\
\hline Toplam & 704 & 100,0 \\
\hline
\end{tabular}

Sosyal medya bozukluğu kapsamında yürütülen mevcut çalışmaya Sağlık Hizmetleri MYO (n=484; \% 68,8), Beden Eğitimi ve Spor Yüksekokulu ( $n=96 ; \% 13,6)$ ile Eğitim fakültesinde ( $n=124 ; \% 17,6)$ öğrenim gören $188^{\prime}$ i erkek (\% 26,7), 516'sı kadın (\% 73,3) olmak üzere toplam 704 öğrenci katılım göstermiştir. Bu öğrencilerin 503'ü $(\% 71,4) 1$. Sinıfta; 142'si (\% 20,2) 2. Sinıfta; 43'ü (\% 6,1) 3. Sinıfta; 10'u (\% 1,4) 4. Sınıfta; 6 'sı ise $(\% 0,9)$ uzatmalı olarak öğrenim görmektedirler. Çalışmaya katılan öğrencilerin 57'si (\% 8,1) günlük 0-1 saat; 263 'ü (\% 37,4) günlük 23 saat; $271^{\prime} i$ (\% 38,5) günlük 4-6 saat; $113^{\prime}$ ü ise (\% 16,1) günlük 7 saat ve üzeri sosyal medyada zaman harcamaktadır. Sosyal medya ağlarından Facebook'u 609 öğrenci (\% 86,5) kullanmıyorken, 95 öğrenci ise (\% 13,5) kullanmaktadır. Instagram'1 146 öğrenci (\% 20,7) kullanmıyorken, 558 öğrenci $(\% 79,3)$ kullandığını ifade etmiştir. Twitter'ı 604 öğrenci (\% 85,8) kullanmıorken, 100 öğrenci (\% 14,2) kullanmaktadır. Whatsapp'1 90 öğrenci $(\%$ 12,8) kullanmamaktayken, 614 öğrenci $(\%$ 87,2) kullandığını ifade etmiştir. Tüm bu sosyal ağların hepsini aynı anda kullanmayan öğrenci sayısı 636 (\%90,3) iken, aynı anda kullanan öğrenci sayısı ise 68 (\% $9,7)^{\prime}$ dir. Sosyal medya ağları içerisinde kullanıma öncelik verilen/en sık kullanılanlar sırası ile; Instagram 354 (\% 50,3) öğrenci, Whatsapp 320 (\% 45,5) öğrenci, Twitter 15 (\% 2,1) öğrenci, diğer sosyal medya $9(\% 1,3)$ 
öğrenci ve Facebook $6(\% 0,9)$ öğrenci şeklindedir. Kendisini sosyal bir birey olarak tanımlayan 456 (\% 64,8) öğrenci var iken, sosyal bir birey olmadığını düşünen 248 (\% 35,2) öğrenci yer almaktadır. Üniversite öğrencilerinin sosyal medya kullanım amaçlarına bakıldığında, 28 öğrenci $(\% 4,0)$ düşünce ve bilgi paylaşımında bulunmak; 335 öğrenci $(\%$ 47,6) zaman geçirmek; 21 öğrenci $(\% 3,0)$ kişileri takip etmek; 164 öğrenci $(\%$ 23,3) güncel haber ve bilgileri takip etmek; 156 öğrenci ise (\% 22,2) iletişim kurmak için sosyal medyayı kullanmakta olduklarını belirtmişlerdir (Tablo 1).

Tablo 2. Sosyal Medya Bozukluğuna İlişkin İstatistikler

\begin{tabular}{cccccccc}
\hline & $\mathrm{N}$ & Ort. & ss. & Çarpıklık & Basıklık & Min. & Mak. \\
\hline $\begin{array}{c}\text { Sosyal Medya } \\
\text { Bozukluğu }\end{array}$ & 704 & 19,01 & 7,32 &, 892 &, 685 & 9 & 45 \\
\hline
\end{tabular}

Öncelikle Sosyal Medya Bozukluğu ölçeğinden alınan toplam puan değişkeninin normal dağılım gösterip göstermediğinin belirlenmesinde Tablo 2' deki çarpıklık ve basıklık değerleri dikkate alınmıştır. Literatürde kabul gören bir kritere göre çarpıklık ve basıklık katsayılarının -1,5 ile 1,5 aralığında olması bir değişkenin normal dağıldığının bir göstergesidir (Tabachnick ve Fidell, 2013). Buna göre, sosyal medya bozukluğu değişkeninin çarpıklık ve basıklık değerleri de göz önüne alındığında bu değişkenin normal dağılım gösterdiği kabul edilebilir. Bu durumda sosyal medya bozukluğu puanlarının çeşitli demografik değişkenler için farklılık gösterip göstermediğinin incelenmesinde parametrik istatistiksel teknikler kullanılacaktır.

\section{Cinsiyete Göre Sosyal Medya Bozukluğu Puanlarının Karşılaştırılması}

Üniversite öğrencilerinin sosyal medya bozukluğunun cinsiyete göre anlamlı bir farklılık gösterip göstermediği bağımsız gruplar için $t$ testi ile incelenmiştir. Sonuçlar Tablo 3'teki gibidir:

Tablo 3. Cinsiyete Göre Sosyal Medya Bozukluğu Puanlarına İlişkin t Testi Sonuçları

\begin{tabular}{cccccc}
\hline Cinsiyet & $\mathbf{N}$ & Ort. & Ss & t & P \\
\cline { 1 - 4 } Erkek & 188 & 18,54 & 7,214 & \multirow{2}{*}{$-1,015$} & \multirow{2}{*}{0,310} \\
\cline { 1 - 3 } & 516 & 19,18 & 7,370 & & \\
\hline
\end{tabular}


Tablo 3'teki $\mathrm{t}$ testi bulgularına göre öğrencilerin sosyal medya bozukluğu ortalama puanlarının cinsiyete göre anlamlı bir farklılık göstermediği söylenebilir ( $t=-1,015 ; \mathrm{p}>0,05)$.

Öğrenim Görülen Bölüm/Fakülteye Göre Sosyal Medya Bozukluğu Puanlarının Karşılaştırılması

Öğrencilerin sosyal medya bozukluğunun öğrenim gördükleri bölüm/fakülte değişkeni açısından anlamlı bir farklılık gösterip göstermediği tek yönlü varyans analizi (ANOVA) ile incelenmiştir. Öğrenim görülen bölüm/fakülte'ye ait betimleyici istatistiklere ve ANOVA testi sonuçlarına sırasıyla Tablo 4 ve Tablo 5'te yer verilmiştir.

Tablo 4. Öğrenim Görülen Bölüm/Fakülte Puanlarna İlişkin Betimleyici İstatistikler

\begin{tabular}{lccc}
\hline Bölüm/Fakülte & N & Ort. & Ss \\
\hline Sağlık Hiz. MYO & 484 & 18,81 & 7,001 \\
\hline BESYO & 96 & 20,80 & 8,512 \\
\hline Eğitim Fakültesi & 124 & 18,40 & 7,453 \\
\hline Toplam & 704 & 19,01 & 7,329 \\
\hline
\end{tabular}

Tablo 5.Öğrenim Görülen Bölüm/Fakülte Puanlarnna İlişskin ANOVA Testi Sonuçları

\begin{tabular}{|c|c|c|c|c|c|}
\hline $\begin{array}{l}\text { Varyans } \\
\text { Kaynağ1 }\end{array}$ & $\begin{array}{l}\text { Kareler } \\
\text { Toplamı }\end{array}$ & $\begin{array}{c}\text { Serbestlik } \\
\text { Derecesi }\end{array}$ & $\begin{array}{c}\text { Kareler } \\
\text { Ortalamas1 }\end{array}$ & $\mathbf{F}$ & $\mathbf{P}$ \\
\hline Gruplar Arası & 374,958 & 2 & 187,479 & \multirow{3}{*}{3,515} & \multirow{3}{*}{0,030} \\
\hline Gruplar İçi & 37386,007 & 701 & 53,332 & & \\
\hline Toplam & 37760,964 & 703 & & & \\
\hline
\end{tabular}

Tablo 5'teki sonuçlar dikkate alındığında, sosyal medya bozukluğu açısından farklı fakülte/bölüm değişkeninin manidar bir farklılık oluşturduğu tespit edilmiştir $(\mathrm{F}=3,515 ; \mathrm{p}<0,05)$. Bu aşamada anlamlı farklılığın hangi fakülte/bölümler arasında kaynaklandığının belirlenmesi için grup varyanslarının homojen olmadığı durumda kullanılan çoklu karşılaştırma testlerinden Tamhane T2 testi yapılmış ve Tablo 6'daki bulgular elde edilmiştir. 
Tablo 6. Öğrencilerin Öğrenim Gördükleri Bölüm/Fakülteye Göre Tamhane T2 Çoklu Karşılaştırma Testi Sonuçları

\begin{tabular}{|c|c|c|c|c|}
\hline Değişken & 1.Grup & 2.Grup & Ortalamalar Fark1 & $\mathrm{P}$ \\
\hline \multirow{6}{*}{ 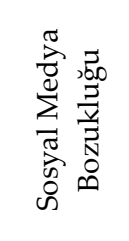 } & \multirow[t]{2}{*}{ Sağlık Hiz. MYO } & BESYO & $-1,994^{*}$ & ,039 \\
\hline & & Eğitim Fakültesi & 413 & 841 \\
\hline & \multirow[t]{2}{*}{ BESYO } & Sağlık Hiz. MYO & $1,994^{*}$ & 039 \\
\hline & & Eğitim Fakültesi & $2,407^{*}$ & ,041 \\
\hline & \multirow[t]{2}{*}{ Eğitim Fakültesi } & Sağlık Hiz. MYO &,- 413 & 841 \\
\hline & & BESYO & $-2,407^{*}$ & ,041 \\
\hline
\end{tabular}

Tablo 6'daki Tamhane T2 çoklu karşılaştırma testi bulguları göz önüne alındığında BESYO'da öğrenim gören öğrencilerinin sosyal medya bozukluklarının hem sağlık hizmetleri meslek yüksekokulunda hem de diğer fakültelerde öğrenim gören öğrencilere göre daha yüksek olduğu söylenebilir.

\section{Sosyal Medyada Geçirilen Süreye Göre Sosyal Medya Bozukluğu Pu- anlarının Karşılaştırılması}

Üniversite öğrencilerinin sosyal medya bozukluğunun günlük sosyal medya kullanma süresi açısından manidar farklılık gösterip göstermediği tek yönlü varyans analizi (ANOVA) ile incelenmiştir. Sosyal medya kullanım süresine göre betimleyici istatistiklere ve ANOVA testi sonuçlarına sırasıyla Tablo 7 ve Tablo 8'de yer verilmiştir.

Tablo 7. Sosyal Medya Kullanım Süresi Puanlarına İlişkin Betimleyici İstatistikler

\begin{tabular}{cccc}
\hline $\begin{array}{c}\text { Sosyal Medya Kullanım Sü- } \\
\text { resi }\end{array}$ & N & Ort. & Ss \\
\hline 0-1 Saat & 57 & 13,47 & 4,591 \\
\hline 2-3 Saat & 263 & 17,02 & 6,281 \\
\hline 4-6 Saat & 271 & 20,25 & 6,703 \\
\hline 7 Saat ve Üzeri & 113 & 23,43 & 8,809 \\
\hline Toplam & 704 & 19,01 & 7,329 \\
\hline
\end{tabular}


Tablo 8. Sosyal Medya Kullanım Süresi Puanlarına İlişkin ANOVA Testi Sonuçlan

\begin{tabular}{|c|c|c|c|c|c|}
\hline $\begin{array}{l}\text { Varyans } \\
\text { Kaynağ1 }\end{array}$ & $\begin{array}{l}\text { Kareler } \\
\text { Toplamı }\end{array}$ & $\begin{array}{c}\text { Serbestlik } \\
\text { Derecesi }\end{array}$ & $\begin{array}{c}\text { Kareler } \\
\text { Ortalaması }\end{array}$ & $\mathbf{F}$ & $\mathbf{P}$ \\
\hline Gruplar Arası & 5420,665 & 3 & 1806,888 & \multirow{3}{*}{39,110} & \multirow{3}{*}{0,000} \\
\hline Gruplar İçi & 32340,299 & 700 & 46,200 & & \\
\hline Toplam & 37760,964 & 703 & & & \\
\hline
\end{tabular}

Tablo 8'deki sonuçlara bakıldı̆̆ında, öğrencilerin sosyal medya kullanım sürelerine göre sosyal medya bozukluk düzeylerinin manidar farklılık oluşturmadığı görülmektedir $(\mathrm{F}=39,110 ; \mathrm{p}<0,05)$. Bu aşamada anlamlılığın hangi kullanım süreleri arasındaki farktan kaynaklandığının belirlenmesi için Tamhane T2 çoklu karşılaştırma testi yapılmış ve Tablo 9'daki bulgular elde edilmiştir.

Tablo 9. Sosyal Medya Kullanım Süresi Puanlarına Göre Tamhane T2 Çoklu Karşılaştırma Testi Sonuçları

\begin{tabular}{|c|c|c|c|c|}
\hline Değişken & 1.Grup & 2.Grup & $\begin{array}{c}\text { Ortalamalar } \\
\text { Fark1 }\end{array}$ & $\mathrm{P}$ \\
\hline \multirow{12}{*}{ 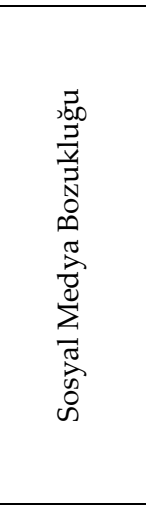 } & \multirow{3}{*}{$0-1$ saat } & 2-3 saat & $-3,545$ & 000 \\
\hline & & 4-6 saat & $-6,781$ & ,000 \\
\hline & & 7 saat ve üzeri & $-9,960$ & ,000 \\
\hline & \multirow{3}{*}{ 2-3 saat } & $0-1$ saat & 3,545 & ,000 \\
\hline & & 4-6 saat & $-3,236$ & ,000 \\
\hline & & 7 saat ve üzeri & $-6,415$ & ,000 \\
\hline & \multirow{3}{*}{ 4-6 saat } & $0-1$ saat & 6,781 & ,000 \\
\hline & & 2-3 saat & 3,236 & ,000 \\
\hline & & 7 saat ve üzeri & $-3,179$ & ,004 \\
\hline & \multirow{3}{*}{7 saat ve üzeri } & 0-1 saat & 9,960 & ,000 \\
\hline & & 2-3 saat & 6,415 & ,000 \\
\hline & & 4-6 saat & 3,179 & ,004 \\
\hline
\end{tabular}

Tablo 9'daki Tamhane T2 çoklu karşılaştırma testi bulguları göz önüne alındığında tüm kullanım süreleri arasında sosyal medya bozukluğu açısından anlamlı farklılıklar olduğu söylenebilir $(\mathrm{p}<0,05)$. Bununla birlikte Tablo 7 'deki gruplara ait ortalama değerleri de dikkate alındığında, öğrencilerin günlük sosyal medya kullanım süreleri arttıkça sosyal medya bozukluklarının da arttığı görülmektedir. Bu bulguya göre üniversite öğrencilerinin sosyal medyayı uzun süre kullanmalarının öğrencilerde sosyal medya bozukluğunu artırdığı söylenebilir. 


\section{En Sık Kullanılan Sosyal Medya Hesabına Göre Sosyal Medya Bo- zukluğu Puanlarının Karşılaştırılması}

Üniversite öğrencilerinin sosyal medya bozukluğunun en sık kullanılan sosyal medya hesabına göre anlamlı bir farklılık gösterip göstermediği yine ANOVA ile incelenmiştir. Tablo 10 ve Tablo 11'de analiz sonuçlarına ter verilmiştir.

Tablo 10. En Sık Kullanılan Sosyal Medya Hesabı Puanlarına İlişkin Betimleyici Ístatistikler

\begin{tabular}{cccc}
\hline $\begin{array}{c}\text { Kullanılan Sosyal Medya } \\
\text { Hesabi }\end{array}$ & $\mathbf{N}$ & Ort. & Ss \\
\hline Facebook & 6 & 18,00 & 5,514 \\
\hline Instagram & 354 & 20,04 & 7,602 \\
\hline Twitter & 15 & 17,33 & 7,853 \\
\hline Whatsapp & 320 & 18,12 & 6,927 \\
\hline Diğer & 9 & 13,67 & 3,606 \\
\hline Toplam & 704 & 19,01 & 7,329 \\
\hline
\end{tabular}

Tablo 11. En Sık Kullanılan Sosyal Medya Hesabı Puanlarına İlişkin ANOVA Testi Sonuçları

\begin{tabular}{|c|c|c|c|c|c|}
\hline $\begin{array}{l}\text { Varyans } \\
\text { Kaynağ1 }\end{array}$ & $\begin{array}{c}\text { Kareler Top- } \\
\text { lamı }\end{array}$ & $\begin{array}{c}\text { Serbestlik } \\
\text { Derecesi }\end{array}$ & $\begin{array}{c}\text { Kareler } \\
\text { Ortalaması } \\
\end{array}$ & $\mathbf{F}$ & $\mathbf{P}$ \\
\hline Gruplar Arası & 934,387 & 4 & 233,597 & \multirow{3}{*}{4,434} & \multirow{3}{*}{0,002} \\
\hline Gruplar İçi & 36826,578 & 699 & 52,685 & & \\
\hline Toplam & 37760,964 & 703 & & & \\
\hline
\end{tabular}

Tablo 11'deki sonuçlara göre öğrencilerin en sık kullandıkları sosyal medya hesabına göre sosyal medya bozukluğu puanları arasında anlamlı bir farklılık görülmektedir $(\mathrm{F}=4,434 ; \mathrm{p}<0,05)$. Farklılığın hangi sosyal medya hesapları arasındaki farktan kaynaklandığının belirlenmesi için Tamhane T2 çoklu karşılaştırma testi yapılmış ve Tablo 12' deki bulgular elde edilmiştir.

Tablo 12' deki Tamhane T2 çoklu karşılaştırma testi bulgularına göre, sadece en sık Instagram'1 kullandığını belirten öğrenciler ile en sik Whatsapp'ı kullandığını ifade eden öğrencilerin sosyal medya bozuklukları arasında anlamlı fark tespit edilmiştir. Tablo 10'daki grup ortalamaları da dikkate alındığında en sık olarak Instagram'ı kullanan 
öğrencilerin Whatsapp'1 kullanan öğrencilere göre sosyal medya bozukluklarının anlamlı düzeyde daha yüksek olduğu söylenebilir.

Tablo 12. En Sik Kullanılan Sosyal Medya Hesabı Puanlarına Göre Tamhane T2 Çoklu Karşılaştırma Testi Sonuçları

\begin{tabular}{|c|c|c|c|c|}
\hline Değişken & 1.Grup & 2.Grup & Ortalamalar Farkı & $\mathrm{P}$ \\
\hline \multirow{20}{*}{ 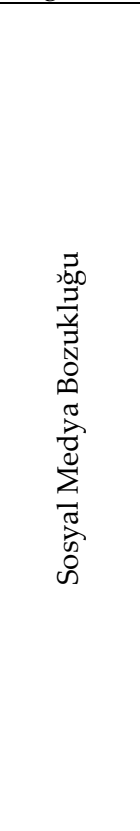 } & \multirow{4}{*}{ Facebook } & Instagram & $-2,037$ & ,960 \\
\hline & & Twitter & 667 & 1,000 \\
\hline & & Whatsapp &,- 116 & 1,000 \\
\hline & & Diğer & 4,333 & 789 \\
\hline & \multirow{4}{*}{ Instagram } & Facebook & 2,037 & ,960 \\
\hline & & Twitter & 2,703 & 620 \\
\hline & & Whatsapp & $1,921^{*}$ & ,006 \\
\hline & & Diğer & 6,370 & 071 \\
\hline & \multirow{4}{*}{ Twitter } & Facebook &,- 667 & 1,000 \\
\hline & & Instagram & $-2,703$ & 620 \\
\hline & & Whatsapp &,- 782 & ,994 \\
\hline & & Diğer & 3,667 & ,753 \\
\hline & \multirow{4}{*}{ Whatsapp } & Facebook & ,116 & 1,000 \\
\hline & & Instagram & $-1,921^{*}$ & ,006 \\
\hline & & Twitter & ,782 & ,994 \\
\hline & & Diğer & 4,449 & 367 \\
\hline & \multirow{4}{*}{ Diğer } & Facebook & $-4,333$ & ,789 \\
\hline & & Instagram & $-6,370$ & ,071 \\
\hline & & Twitter & $-3,667$ & ,753 \\
\hline & & Whatsapp & $-4,449$ & ,367 \\
\hline
\end{tabular}

Kendisini Sosyal Bir Birey Olarak Tanımlama Durumuna Göre Sosyal Medya Bozukluğu Puanlarının Karşılaştırılması

Üniversite öğrencilerinin sosyal medya bozukluk düzeylerinin sosyal bir birey olup olmadıkları açısından farklııı yaratıp yaratmadığı, bağımsız gruplar için t testi ile incelenmiştir. Sonuçlar Tablo 13'teki gibidir:

Tablo 13. Sosyallik Durumuna Göre t Testi Sonuçları

\begin{tabular}{ccccccc}
\hline $\begin{array}{c}\text { Kendinizi Sosyal Bir Birey } \\
\text { Olarak Tanımliyor musunuz? }\end{array}$ & N & Ort. & ss & T & P \\
\cline { 1 - 4 } Evet & 456 & 18,55 & 7,053 & & $-2,176$ & 0,030 \\
\hline Hayır & 248 & 19,84 & 7,756 &
\end{tabular}


Tablo 13'teki t testi bulgularına göre öğrencilerin kendilerini sosyal bir birey olarak tanımlama durumlarının sosyal medya bozukluğu ortalama puanları üzerinde manidar farklılık oluşturduğu görülmektedir $(t=-2,176$; $\mathrm{p}<0,05)$. Bununla birlikte grup ortalamaları da dikkate alındığında kendisini sosyal bir birey olarak tanımlamayan öğrencilerin sosyal medya bozukluk düzeylerinin sosyal biri olduğunu ifade eden öğrencilere göre daha yüksek olduğu görülmektedir. Bu bulgudan yola çıkarak üniversite öğrencilerinin sosyallik düzeyleri arttıkça sosyal medya bozukluk düzeylerinin anlamlı derecede azaldığı söylenebilir.

\section{Sosyal Medyayı Kullanma Amacına Göre Sosyal Medya Bozukluğu Pu- anlarının Karşılaştırılması}

Kullanılan sosyal medya hesaplarının kullanım amaçları açısından sosyal medya bozukluğu üzerinde anlamlı bir farklılığa sebep olup olmadığ yine ANOVA ile incelenmiştir. Analiz sonuçlarına sırasıyla Tablo 14 ve Tablo 15 'te yer verilmiştir.

Tablo 14. Sosyal Medya Kullanım Amacı Puanlarına İlişkin Betimleyici İstatistikler

\begin{tabular}{lccc}
\hline Kullanım amacı & N & Ort. & Ss \\
\hline Düşünce ve Bilgi Paylaşmak & 28 & 17,11 & 5,698 \\
\hline Zaman Geçirmek & 335 & 19,89 & 7,348 \\
\hline Kişileri Takip Etmek & 21 & 27,76 & 9,889 \\
\hline Güncel Haber ve Bilgileri Takip Etmek & 164 & 17,85 & 6,685 \\
\hline İletişim Kurmak & 156 & 17,49 & 6,751 \\
\hline Toplam & 704 & 19,01 & 7,329 \\
\hline
\end{tabular}

Tablo 15. Sosyal Medya Kullanım Amacı Puanlarına İlişkin ANOVA Testi Sonuçları

\begin{tabular}{cccccc}
\hline $\begin{array}{c}\text { Varyans } \\
\text { Kaynağı }\end{array}$ & $\begin{array}{c}\text { Kareler } \\
\text { Toplamı }\end{array}$ & $\begin{array}{c}\text { Serbestlik } \\
\text { Derecesi }\end{array}$ & $\begin{array}{c}\text { Kareler } \\
\text { Ortalaması }\end{array}$ & F & P \\
\cline { 1 - 4 } Gruplar Arası & 2545,305 & 4 & 636,326 & \multirow{2}{*}{12,631} & \multirow{2}{*}{0,000} \\
\cline { 1 - 4 } Gruplar İçi & 35215,659 & 699 & 50,380 & & \\
\hline Toplam & 37760,964 & 703 & & &
\end{tabular}

Tablo 15'teki sonuçlara göre öğrencilerin sosyal medya bozukluk düzeyleri sosyal medyayı kullanma amaçlarına göre anlamlı bir farklılık göstermektedir $(F=12,631 ; p<0,05)$. Oluşan manidar farklılığ1 tespit etmek amacıyla yapılan Tamhane T2 testi sonuçları ise Tablo 16'daki gibidir. 
Tablo 16. Kullanılan Sosyal Medya Hesabı Amacına Göre Tamhane T2 Çoklu Karşılaştırma Testi Sonuçları

\begin{tabular}{|c|c|c|c|c|}
\hline Değişken & 1.Grup & 2.Grup & $\begin{array}{l}\text { Ortalamalar } \\
\text { Fark1 }\end{array}$ & $\mathrm{P}$ \\
\hline \multirow{20}{*}{ 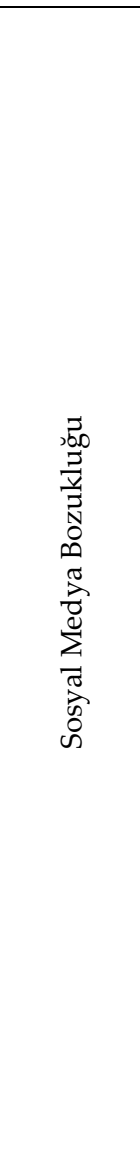 } & \multirow{4}{*}{$\begin{array}{l}\text { Düşünce ve Bilgi } \\
\text { Paylaşmak }\end{array}$} & Zaman Geçirmek & $-2,779$ & 191 \\
\hline & & Kişileri Takip Etmek & $-10,655^{*}$ & ,001 \\
\hline & & $\begin{array}{l}\text { Güncel Haber ve Bilg- } \\
\text { ileri Takip Etmek }\end{array}$ &,- 747 & 1,000 \\
\hline & & İletişim Kurmak &,- 386 & 1,000 \\
\hline & \multirow{4}{*}{ Zaman Geçirmek } & $\begin{array}{l}\text { Düşünce ve Bilgi } \\
\text { Paylaşmak }\end{array}$ & 2,779 & 191 \\
\hline & & Kişileri Takip Etmek & $-7,875^{*}$ & ,017 \\
\hline & & $\begin{array}{l}\text { Güncel Haber ve Bilg- } \\
\text { ileri Takip Etmek }\end{array}$ & $2,033^{*}$ & ,022 \\
\hline & & İletişim Kurmak & $2,393^{*}$ & ,004 \\
\hline & \multirow{4}{*}{$\begin{array}{l}\text { Kişileri Takip Et- } \\
\text { mek }\end{array}$} & $\begin{array}{l}\text { Düşünce ve Bilgi } \\
\text { Paylaşmak }\end{array}$ & $10,655^{*}$ & ,001 \\
\hline & & Zaman Geçirmek & $7,875^{*}$ &, 017 \\
\hline & & $\begin{array}{l}\text { Güncel Haber ve Bilg- } \\
\text { ileri Takip Etmek }\end{array}$ & $9,908^{*}$ & ,002 \\
\hline & & İletişim Kurmak & $10,268^{*}$ &, 001 \\
\hline & \multirow{4}{*}{$\begin{array}{l}\text { Güncel Haber ve } \\
\text { Bilgileri Takip Et- } \\
\text { mek }\end{array}$} & $\begin{array}{l}\text { Düşünce ve Bilgi } \\
\text { Paylaşmak }\end{array}$ & ,747 & 1,000 \\
\hline & & Zaman Geçirmek & $-2,033^{*}$ &, 022 \\
\hline & & Kişileri Takip Etmek & $-9,908^{*}$ &, 002 \\
\hline & & İletişim Kurmak & ,360 & 1,000 \\
\hline & \multirow{4}{*}{ İletişim Kurmak } & $\begin{array}{l}\text { Düşünce ve Bilgi } \\
\text { Paylaşmak }\end{array}$ & ,386 & 1,000 \\
\hline & & Zaman Geçirmek & $-2,393^{*}$ & , 004 \\
\hline & & Kişileri Takip Etmek & $-10,268^{*}$ & ,001 \\
\hline & & $\begin{array}{l}\text { Güncel Haber ve Bilg- } \\
\text { ileri Takip Etmek }\end{array}$ &,- 360 & 1,000 \\
\hline
\end{tabular}

Tablo 16'daki Tamhane T2 testi bulgularına göre sosyal medyayı kişileri takip etmek amacıyla kullanan öğrencilerin sosyal medya bozukluk düzeylerinin diğer amaçlar için kullanan öğrencilerin tamamına göre anlamlı derecede daha yüksek olduğu görülmektedir. Yine Tablo 16'daki bir diğer bulguya göre sosyal medyayı zaman geçirmek amacıyla kullanan öğrencilerin sosyal medya bozukluk düzeyleri sosyal medyayı güncel haber ve bilgileri takip etmek ve iletişim kurmak amacıyla kullanan öğrencilere göre anlamlı derecede daha yüksektir. 


\section{Tartışma}

Mevcut çalışmada, kadın ve erkek öğrenciler arasında sosyal medya bozukluğu açısından herhangi bir farklılık tespit edilememiştir. Benzer şekilde, Aydın (2016) tarafından yapılan çalışmada da, kadın ve erkek öğrenciler arasında herhangi bir farklılığa rastlanılmamıştır. Aktan (2018)'ın öğrenciler üzerinde yapmış olduğu sosyal medya bağllı̆̆ ilgili araştırmada kadın ve erkekler arasında farklılık olmadığı belirlenmiştir. İçirgin (2018) tarafından yapılan çalışmada da kadın ve erkek öğrencilerin sosyal medya kullanım alışkanlığı ve motivasyonlarında farklılık tespit edilmemiştir. Çiftçi (2018) de, benzer şekilde kız ve erkek öğrencilerin sosyal medya bağlılığında farklılık oluşmadığını ifade etmiştir. Gürültü (2016), lise öğrencileri üzerinde yaptığı çalışmasında sosyal medya bağımlılığı puanının cinsiyete göre farklılaşmadığını belirtmiştir. $\mathrm{Bu}$ çalışmaların bulguları, mevcut çalışmanın cinsiyet değişkenine ilişkin bulgusu ile benzerlik göstermektedir.

Çalışmanın bir diğer bulgusu öğrencilerin farklı bölümlerde öğrenim görmesinin sosyal medya bozukluk düzeylerinde anlamlı farklılık oluşturmasıdır. Benzer şekilde Çiftçi (2018), farklı bölümlerde öğrenim gören öğrenciler arasında sosyal medya bağımlılığında anlamlı farklılık ortaya çıktığını tespit etmiştir.

Mevcut çalışmada öğrencilerin sosyal medya kullanım süresinin sosyal medya bozukluk düzeylerinde anlamlı farklılığa neden olduğu tespit edilmiştir. O'Toole tarafından yapılan çalışmada, haftada beş saatten fazla internet kullanan bireylerin dörtte birlik kesiminin, internetin bireylerin ailelerine ve arkadaşlarına ayırmaları gereken zamanı azalttığına inandıkları saptanmıştır (O'Toole, 2000). Sanders ve ark., ergenler üzerinde yapılan incelemede, ergenlerin internet fazla kullanmalarının, aile ve arkadaş ilişkilerini azaltığı sonucuna varılmıştır (Sanders ve ark., 2000).

Aydın (2016) çalışmasında öğrencilerin internet kullanım sürelerinde farklılıklar ortaya çıtığını ifade etmiş, Aktan (2018) ise öğrencilerin sosyal medya kullanım süreleri arasında manidar farklılıklar oluştuğunu belirlemiştir. Demir (2016)'in lise öğrencileri ile yapmış olduğu çalışmada sosyal medya kullanım sıklığında farklılıklar tespit edilmiştir. Konuyla 
direkt benzerlik gösteren Gürültü (2016)'nün çalışmasında ise lise öğrencilerinin sosyal medya bağımlılığı puanlarının sosyal medya kullanım sıklığı değişkenine göre anlamlı bir farklılık gösterdiği tespit edilmiştir. Bener şekilde Okumuş (2018) öğrencilerin sosyal medya tutum puanlarının, sosyal medya kullanım sıklığı değişkenine göre anlamlı bir farklılık oluşturduğunu tespit etmiştir. Tüm bu bulgular, mevcut çalışma sonucu ile örtüşmekte iken, İçirgin (2018)'in üniversite öğrencilerinin sosyal medya kullanım alışkanlıkları ve motivasyonlarının, sosyal medya kullanma sıklıklarına göre anlamlı farklılık göstermediğini vurgulaması, çalışma sonucu ile benzerlik göstermemektedir.

Mevcut çalışma sonuçları, en sık kullanılan sosyal medyanın Instagram ve Whatsapp olduğunu göstermiştir. Yapılan bir çalışma ise (Mazman, 2009) facebook kullanımının yaygın olarak kullanıldığını göstermiştir.

\section{Sonuç}

Çalışmaya katılan tüm öğrencilerin sosyal medya bozukluğu puan ortalaması $(\bar{X}=19,01)$ olarak hesaplanmış, buna göre üniversite öğrencilerinin sosyal medya bozukluğunun düşük düzeyde olduğu belirlenmiştir. Bu bulgu, öğrencilerin sosyal hayatta çevreleri ile daha fazla ve sağlam ilişkiler kurduklarını göstermektedir.

Mevcut çalışmada, kadın ve erkek öğrenciler arasında sosyal medya bozukluğu açısından herhangi bir farklılık tespit edilememiştir. Ağ teknolojisinin gelişmişliğine bağlı olarak sosyal medya kullanım alanları ve süresi de git gide artmaktadır. Toplumda hem kadınlar hem de erkekler, sosyal medyaları aktif bir şekilde kullanmaktadırlar. Ancak bu kullanım, her iki cinsiyet arasında herhangi bir farklılık ortaya çıkarmamaktadır.

Öğrencilerin farklı bölümlerde öğrenim görmesi sosyal medya bozukluk düzeylerinde farklılığa neden olmaktadır. Araştırmanın bulgularına bakıldığında BESYO'da öğrenim gören öğrencilerin sosyal medya kullanım bozukluğunun daha yüksek olduğu görülmektedir. BESYO'larda derslerin yoğunlukla uygulamalı olarak işlenmesi ve bu vesile ile serbest zamanların diğer öğrencilere oranla daha fazla olması nedeniyle BESYO öğrencilerinin sosyal medya kullanım sürelerinin daha 
fazla olabileceği, bu durumda sosyal medya kullanım bozukluğunun da artabileceği söylenebilir.

Öğrencilerin günlük sosyal medya kullanım süresinin sosyal medya bozukluğunda farklılık yarattığı tespit edilmiştir. Elde edilen bulgulara bakıldığında kullanım süresi 7 saat ve üzeri olan öğrencilerin sosyal medya bozukluğu ortalamasının en yüksek olduğu tespit edilmiştir. Ortaya çıkan bu sonuç, sosyal medya kullanım süresi ne kadar az olur ise, sosyal medya bozukluğunun da o düzeyde düşük olacağını göstermektedir.

En sık kullanılan sosyal medyanın, öğrencilerin sosyal medya bozukluğu üzerinde farklılık oluşturduğu belirlenmiştir. Sosyal medya kullanım süresi arttıkça, sosyal medya bozukluğunun da yükselmesi aşikârdır. Bu nedenle, sıklıkla kullanılan sosyal medyalar arasında farklılıklar olması, beraberinde kullanım bozukluğunda da farklılık yaratmıştır. Araştırmada sosyal medya bozukluğu en yüksek olan öğrencilerin en sıklıkla Instagram kullanıcısı olan öğrenciler olduğu, bunu en sık Whatsapp kullandığını belirten öğrencilerin izlediği belirlenmiştir.

Araştırma kapsamında kendini sosyal bir birey olarak tanımlamayan öğrencilerin ortalama sosyal medya bozukluk puanlarının yüksek olduğu belirlenmiştir. Birey sosyal bir yapıya sahip olmaz ise, çevresi ile iletişime kapalı olacaktır. Bu durum da bireyi telefon, bilgisayar, tablet gibi kişinin asosyal bir ortamda vakit geçireceği kanallara yöneltecektir. Bu bağlamda birey daha fazla sosyal medyada zaman harcayacak ve sosyal medya bozukluğu da yüksek çıkacaktır. Buna göre üniversite öğrencilerinin sosyal medya bozukluğunu düşürmenin bir yolu olarak gerçek hayattaki sosyal etkinliklerinin artırılması önerilmektedir.

Öğrencilerin sosyal medyayı kullanma amaçlarının da sosyal medya bozukluk düzeylerinde farklılığa neden olduğu belirlenmiştir. Bulgular dikkate alındığında, sosyal medya bozukluğu en yüksek olan öğrencilerin sosyal medyayı kişileri takip etmek amacıyla kullanan öğrenciler olduğu tespit edilmiştir. Ayrıca son olarak sosyal medyayı zaman geçirmek amacıyla kullanan öğrencilerin sosyal medya bozukluk düzeylerinin sosyal medyayı güncel haber ve bilgileri takip etmek ve iletişim kurmak amacıyla kullanan öğrencilere göre daha yüksek olduğu belirlenmiştir. 
EXTENDED ABSTRACT

\section{Social Media Disorder: A Research on University Students

\author{
Çağdaş Caz - Sait Bardakçı \\ Yozgat Bozok University - Cumhuriyet University
}

Internet and social media have become an indispensable part of our daily life. Social media has become the focus of everyone who can use electronic gadgets. Social media and internet sites are increasing the number of users every day. The developments in information and communication technologies have brought along some risks as well as these opportunities. One of these risks is social media disorder. social media networks, as well as useful for individuals to take their time out of the function and also cause negative consequences such as use. The present study is important for the determination of social media impairment levels of university students. The aim of this study is to determine the social media disorder levels of university students and to examine the social media disorders of the students in terms of the different variables they have.

\section{Method}

The universe of the study is composed of all Yozgat Bozok University students. The sample of the study consists of a total of 704 students studying at the Vocational School of Health Services, School of Physical Education and Sports and other faculties. Easy sampling method was used to determine the study group. The sampling method is a sampling technique that allows fast, cheap and easy data collection (Gürbüz and Şahin, 2014).

\section{Data Collection Tool}

Social Media Disorder Scale was used as the data collection tool. The scale is a 5-point Likert-type scale consisting of 9 items. 


\section{Data Collection}

Data were collected from university students during the course period. Before the data collection tool was distributed to the students, information was given about the study. As the study was based on the principle of voluntary participation, data were collected from students who wanted to participate in the study.

\section{Data Analysis}

Firstly, Kolmogorov-Smirnov test was used in order to determine whether the obtained data was normally distributed. The number of categories was taken into consideration when comparing the demographic characteristics of university students according to different categories of social media disorder scores. According to this, $t$-test was used for independent groups for two-variable variables, and one-way variance analysis (ANOVA) was used for variables with three or more categories. In order to determine the difference between the groups, if there is any difference between the ANOVA tests, multiple comparison (Post Hoc.) Tests are used. In the determination of the multiple comparison test to be used Levene test of homogeneity of variance was taken into consideration. As a result of this test, Tukey, if the group variances were homogeneous, Tamhane T2 multiple comparison test was used.

\section{Findings}

Considering the skewness and kurtosis values of the social media disorder variable, it can be assumed that this variable has a normal distribution. In this case, parametric statistical techniques will be used to investigate whether social media disorder scores differ for various demographic variables. 


\section{Discussion}

In the present study, no difference was found between the male and female students in terms of social media disorder. Similarly, the study conducted by Aydin (2016) did not reveal any differences between male and female students. Aktan (2018)'s research on social media loyalty to students revealed no difference between men and women. In the present study, it was determined that the social media usage period of the students caused a significant difference in social media disorder levels. Aydin (2016) stated that there were differences in the internet usage period of the students and Aktan (2018) determined that there were significant differences between the social media usage period of the students. Another finding of this study is that students' education in different departments makes a significant difference in social media disorder levels. Similarly, Farmer (2018) found that there was a significant difference in social media addiction among students studying in different departments.

\section{Results}

In the present study, no difference was found between the male and female students in terms of social media disorder. Depending on the development of network technology, social media usage areas and duration are increasing. In society, both women and men actively use social media. However, this use does not reveal any difference between the two genders. Students' learning in different departments leads to differences in social media levels. When the findings of the study are examined, it is seen that the social media use disorder of the students studying at BESYO is higher. It has been determined that daily social media usage of students makes a difference in social media disorder. According to the findings obtained, it was determined that the average of social media disorder of students with a duration of 7 hours or more was the highest. This result shows that the less social media usage period, the lower the level of social media disorder. It was determined that the most frequently used social media had a difference on the social media disorder of the students. As the duration of social media usage increases, it is obvious that social media disorder also increases. 


\section{Kaynakça / References}

Akkaya, Ö. ve Zerenler, M. (2017). Social media and sports marketing relationship a research toward identification of fan's attitudes: Beşiktaş sports club example. Süleyman Demirel Üniversitesi İktisadi ve İdari Bilimler Fakültesi Dergisi, 22(4), 945-963.

Aktan, E. (2018). Üniversite öğrencilerinin sosyal medya bağımlılık düzeylerinin çeşitli değişkenlere göre incelenmesi. Erciyes İletişim Dergisi, 5(4), 405-421.

Aydın, İ. E. (2016). Üniversite öğrencilerinin sosyal medya kullanımları üzerine bir araştırma: Anadolu üniversitesi örneği. Selçuk Üniversitesi Sosyal Bilimler Enstitüsü Dergisi, 6(35), 373-386.

Cabral, J. (2011). Is generation addicted to social media. The Elon Journal of Undergraduate Research in Communications, 2(1), 1-10.

Çiftçi, H. (2018). Üniversite öğrencilerinde sosyal medya bağımlılı̆̆ı. $M A$ NAS Sosyal Araştırmalar Dergisi, 7(4), 417-434.

Demir, Ü. (2016). Sosyal medya kullanımı ve aile iletişimi: Çanakkale'de lise öğrencileri üzerine Bir araştırma. Selçuk İletişim, 9(2), 27-50.

Dikme, G. (2013). Üniversite öğrencilerinin iletişimde ve günlük hayatta sosyal medya kullanım alışkanlıkları: kadir has üniversitesi örneği. Yüksek Lisans Tezi, Kadir Has Üniversitesi, İstanbul.

Ergenç, A. (2011). Web 2.0 ve sanal sosyalleşme: facebook örneği. Yüksek Lisans Tezi, Maltepe Üniversitesi, İstanbul.

Göksel, A. G. ve Serarslan, M. Z. (2015). Public relations in sports clubs: New media as a strategic corporate communication instrument. International Journal of Physical Education, Sports and Health, 2(2), 275-283.

Griffiths, M. D. Szabo, A. (2014). Is excessive online usage a function of medium or activity? An empirical pilot study. J Behav Addict, 3, 7477.

Gürbüz, S. ve Şahin, F. (2014). Sosyal bilimlerde araştırma yöntemleri. 2. Baskı. Ankara: Seçkin Yayıncılık.

Gürültü, E. (2016). Lise öğrencilerinin sosyal medya bağımlılıkları ve akademik erteleme davranışları arasındaki ilişkinin incelenmesi. Yüksek Lisans Tezi, Marmara Üniversitesi, İstanbul. 
Hazar, M. (2011). Sosyal medya bağımlılığı bir alan çalışması. İletişim Kuram ve Araştırma Dergisi, 2, 151-175.

İçirgin, Ö. (2018).Üniversite öğrencilerinin sosyal medya kullanım alışkanlıkları ve motivasyonları. Yüksek Lisans Tezi, Selçuk Üniversitesi, Konya.

İşlek, M. S. (2011) Sosyal medyanın tüketici davranışlarına etkileri: Türkiye'deki sosyal medya kullanıcılar üzerine bir araştırma. Yüksek Lisans Tezi, Karamanoğlu Mehmetbey Üniversitesi, Karaman.

Karagöz, Y. (2016). SPSS ve Amos 23 uygulamal istatistiksel analizler. 1. Basım, Ankara: Nobel Yayıncilik.

Karasar, N. (1991). Bilimsel araştırma yöntemi. Ankara: Nobel Yayıncılık.

Kırık, A. M. Arslan, A. Çetinkaya, A. ve Gül, M. (2015). A quantitative research on the level of social media addiction among young people in Turkey. International Journal of Science Culture and Sport (Intjscs), 3(3), 108-122.

Lim, Y. ve An, S. (2018). Effects of attributions and social media exposure on obesity stigma among korean adolescents. Social Behavior and Personality, 46(12), 2049-2062.

Mazman, G. (2009). Sosyal ağların benimsenme süreci ve eğitsel bağlamda kullanımı. Yüksek Lisans Tezi, Hacettepe Üniversitesi, Ankara.

Mitchell, F. R. Santarossa, S. ve Woodruff, S. J. (2018). Athletes as advocates: Influencing eating-disorder beliefs and perceptions through social media. International Journal of Sport Communication, 11, 433446.

Okumuş, V. (2018). Çocukların sosyal medya kullanımları ile ebeveyn tutumları arasındaki ilişkinin incelenmesi. Yüksek Lisans Tezi, İstanbul Ticaret Üniversitesi, İstanbul.

Patchin, J. ve Hinduja, S. (2006). Bullies move beyond the schoolyard: a preliminary look at cyber bullying. Youth Violence and Juvenile Justice, 4(2), 148-169.

Sarıçam, H. ve Adam-Karduz, F. F. (2018). Sosyal medya kullanım bozukluğu ölçeği'nin Türk kültürüne uyarlanması: geçerlik ve güvenirlik çalışması. Eğitimde ve Psikolojide Ölçme ve Değerlendirme Dergisi, 9(2), 116-135.

Savcl, M. Ercengiz, M. ve Aysan, F. (2018). Sosyal Medya bozukluğu ölçeği'nin ergenlerde Türkçe uyarlaması. Arch Neuropsychiatry DOI 10.5152npa.2017.19285. 
Sanders, C., Field, T., Diego, M. ve Kaplan, M. (2000). The relationship of internet use to depression and social isolation among adolescents. Adolescence, 35, 237-242.

Singh, N. ve Barmola, K. C. (2015). Internet Addiction, mental health and academic performance of school students/adolescents. The International Journal of Indian Psychology, 2(3), 98-108.

Tabachnick, B. G. ve Fidell, L. S. (2013). Using multivariate statistics. (sixth ed.), Boston: Pearson.

Ünlü, F. (2018). Orta yaş üstü bireylerde sosyal medya bağımlılığı ve sosyal izolasyon. PESA Uluslararası Sosyal Araştırmalar Dergisi, 4(1), 161-171.

Yayla, K. (2010). Internet pazarlamasında yeni eğilimler: çevrimiçi sosyal ağlarm üniversite öğrencilerinin satın alma davranışlarına etkisi. Yüksek Lisans Tezi, Celal Bayar Üniversitesi, Manisa.

\section{Kaynakça Bilgisi / Citation Information}

Caz, Ç. ve Bardakçı, S. (2019). Sosyal medya bozukluğu: Üniversite öğrencileri üzerine bir araştırma. OPUS-Uluslararası Toplum Araştırmaları Dergisi, 10(17), 1100-1124. DOI: 10.26466/opus.521522 